\title{
When Does Christian Religion Matter for Entrepreneurial Activity? The Contingent Effect of a Country's Investments into Knowledge
}

\author{
K. PRAVEEN PARBOTEEAH \\ Management Department \\ University of Wisconsin - Whitewater \\ Whitewater, WI 53190 \\ Tel: + 1262 472-3971 \\ Fax: + 1262 472-4863 \\ Email:parbotek@uww.edu \\ SASCHA G. WALTER \\ Lancaster University \\ Lancaster, LA1 4YX, UK \\ Tel: +44 1524594847 \\ Fax: +44 152494743 \\ Email: s.walter@lancaster.ac.uk \\ JÖRN BLOCK \\ University of Trier \\ Trier, 54296, Germany \\ Tel: +496512013030 \\ Fax: +496512013029 \\ Email: block@uni-trier.de
}

Journal of Business Ethics (forthcoming)

The final publication is available at Springer via http://dx.doi.org/10.1007/s10551-014-2239-z

\begin{abstract}
This study furthers scholarship on the religion-entrepreneurship link by proposing that (1) aspects of a country's religious profile impact individual entrepreneurial activity differently and (2) that a country's level of investments in knowledge serves as a contingency factor in this milieu. Our cross-level analyses of data from 9,266 individuals and 27 predominantly Christian countries support the second, but not the first suggestion. The study contributes to a more nuanced understanding of religion's role for entrepreneurship and bridges the literatures on religion and knowledge-based entrepreneurship. Furthermore, the study provides evidence of the effects of religion above and beyond the effects of national culture.
\end{abstract}

Keywords Entrepreneurial activity, religion, spirituality, cross-level analysis

Acknowledgements: Valuable comments by two anonymous reviewers and editorial guidance by Domènec Melé are gratefully acknowledged. We also thank Sarah Drakopoulou Dodd and Bruno Dyck for helpful comments on prior versions of the paper. 


\section{Introduction}

The interest in understanding entrepreneurship from a cross-national perspective has not waned (Cullen et al. forthcoming). This is not surprising given the importance of entrepreneurship to a nation's economic growth and development (Pinillos \& Reyes 2011). However, cross-national research to understand why rates of entrepreneurship differ among countries has either focused on institutional drivers (e.g., Baker et al. 2005; Busenitz et al. 2000) or cultural aspects (e.g., Liñán \& Fernandez-Serrano 2014; Stephan \& Uhlaner 2010; Uhlaner \& Thurik 2007). Furthermore, the extant literature suggests that the cultural approach has dominated such studies although no consensus has emerged about the role of culture in influencing entrepreneurship (e.g., Hayton et al. 2002; Hayton \& Cacciotti 2013). While this line of research has contributed greatly to our understanding of cross-national levels of entrepreneurship, religion has mostly been ignored in large scale, cross-national studies.

The idea that religion - the sets of beliefs, activities and institutions based on faith in supernatural forces (Stark \& Bainbridge 1985) — is linked to entrepreneurship is hardly novel. Weber's (1930) seminal work on the Protestant Ethic and the Spirit of Capitalism laid the foundation to understand the mechanisms of how religion, an arguably personal attribute, can become prevalent in society and affect societal members. While Weber's (1930) thesis remains popular (Ryman \& Turner 2007), more recent scholarship shows that the question of how religion broadly impacts the creation of new businesses remains topical (Audretsch et al. 2013; Choi 2010; Dana 2009; Drakopoulou Dodd \& Gotsis 2007; Drakopoulou Dodd \& Seaman 1998; Galbraith \& Galbraith 2007; Gotsis \& Kortezi 2009; Essers \& Benschop 2009; Neubert \& Beard 2013; Valliere 2008). These studies can be viewed as part of a recent "theological turn" in the wider field of management and organizational studies, basically suggesting that religion 'supports' business (Dyck in press). 
Prior research has typically argued that religion provides a context promoting the ability and/or motivation of individuals to exploit a given entrepreneurial opportunity (e.g., Furnham \& Koritsas 1990; Weber [1922] 1978). It has neglected cross-country differences in the supply with opportunities often resulting from differences in the national rates of technological change and knowledge accumulation (Schumpeter 1934; Shane \& Venkataraman 2000). Although countries with identical religious profiles may provide the same supportive environment, the more knowledge-driven and technologically advanced countries tend to offer more entrepreneurial opportunities (Jaffe et al. 1993; Keller 2002) that can be identified and exploited by individuals (Acs et al. 2009; Baker et al. 2005). In other words, theorizing about national differences in the link between religion and entrepreneurship may require the consideration of a country's level of investments into new knowledge and technology. Previous studies have overlooked the possibility that such knowledge investments might be an important boundary condition in the religion-entrepreneurship relationship. This is surprising given the long-standing debate about the interplay between technology and religion (Drees 2002; Kong 2001; White 1978). For instance, Noble (2013: 5) notes "Perhaps nowhere is the intimate connection between religion and technology more manifest than in the United States, where an unrivaled popular enchantment with technological advance is matched by an equally earnest popular expectation of Jesus Christ's return.”

In addition, prior scholarship examining religion and entrepreneurship tended to rely on single manifestations of religion (e.g., Galbraith \& Galbraith 2007). Rather than being a unidimensional construct, religion is suggested to include distinct and unique dimensions (DeJong et al. 1976; Parboteeah et al. 2009a)—with potentially differential effects on entrepreneurial activity. Moreover, although Weber's ([1922] 1978) original articulation of the link between religion and entrepreneurship was cross-level, most studies only consider the individual level. For instance, Dana (2009) and Drakopoulou Dodd and Gotsis (2007) acknowledge the cross-level nature of the relationship but their reviews of studies show 
scholarship at single levels of analysis. Focusing on individual religiosity bears the risk of neglecting that religion can create behavioral norms also relevant for non-believers (Adamczyk \& Palmer 2008). More research from a contextual perspective on religion is thus warranted.

Given the above gaps, our study makes two key arguments. First, we suggest that a country's religious aspects (as proposed by Parboteeah et al. 2009a) have differential effects on an individual's probability to become an entrepreneur. Second, we draw on prior work on knowledge investments and spillovers to argue that the relationship between religious aspects and entrepreneurial activity is contingent upon a country's level of knowledge investments (Acs et al. 2009; Audretsch \& Lehmann 2005). Moreover, given its close relationship to a country's religious profile (Cullen et al. forthcoming), we also explore the multifaceted influences of national culture in the context of our study (Hayton et al. 2002; Hayton \& Cacciotti 2013). Overall, our study contributes to a more refined understanding of the impact of religion on entrepreneurship.

\section{Theory}

Religion remains an important variable that continues to attract research interest (e.g., Barro \& McCleary 2005; Parboteeah et al. 2009a). Weber's (1930) seminal work on the Protestant Ethic and the Spirit of Capitalism laid the foundation to understand the broad impact of religions and religious institutions on economic activity. Weber argued that God's favor was indicated through personal economic success. This belief led Protestant congregations to work harder, save and reinvest money and find better ways of doing things (Ryman \& Turner 2007). According to Weber ([1922] 1978: 588), "Protestantism interpreted success in business as the fruit of a rational mode of life." Weber's theory encompasses various types of entrepreneurs, ranging from Kirzner's (1973) 'arbitrageur' to Schumpeter's (1934) 'destroyer 
of markets'. His work thus provided some initial insights into the mechanisms of how religion, an arguably personal attribute, can become prevalent in society and affect societal members.

A key notion in Weber's work is that individual behavior is guided by religious context. As Weber (1930:120) notes: "With the consciousness of standing in the fullness of God's grace and being visibly blessed by Him, the bourgeois business man, as long as he remained within the bounds of formal correctness [...] could follow his pecuniary interests [...]. The power of religious asceticism provided him in addition with sober, conscientious, and unusually industrious workmen, who clung to their work as to a life purpose willed by God." This notion is also reflected in contextual theory with its basic assumption that the context within which the individual operates has effects above and beyond personal characteristics of individuals (Kelley \& De Graaf 1997).

Contextual theory allows us to theoretically link country-level religiosity and entrepreneurship (Lim \& MacGregor 2012). Specifically, as argued by Kelley \& DeGraaf (1997), religions are important social institutions that provide norms to distinguish acceptable from unacceptable behaviors (Parboteeah et al. 2009a). As such, for societal members to remain in good standing, they feel obliged to respect and abide by these norms. Furthermore, even if someone is not religious and that person resides in a more religious environment, "religion enters freely into everyday interaction and becomes part of the normative system" (Stark \& Bainbridge 1996: 164). The process of social interaction as well as indirect social control and support thus result in moral communities (Stark \& Bainbridge 1996) whereby religion has important influences on individuals irrespective of their individual religiosity. Thus, as argued by Dana (2009: 87), "Regardless of whether a person is religious, he or she is influenced by the values propagated by religion." We similarly assume that the religious context will influence societal members' desire to become entrepreneurs independent of their personal characteristics. 
The study by Adamczyk and Palmer (2008) provides some understanding of the contextual effects of religion in the case of drug use. They mention that most previous research has shown that individual religiosity is often linked to lower drug use. However, they also propose that individuals in more religious context are also less likely to use drugs irrespective of their personal degree of religiosity. They argue that individuals who are in more religious contexts are more likely to interact with others who are religious. Because most religions tend to proscribe drug use, individuals in religious contexts are more likely to be exposed to environments discouraging drug use. To remain in good standing with their peers and to maintain conformity, such individuals are less likely to use drugs. This is true irrespective of whether the individual is an atheist or has strong religiosity. In both cases, the individual will want to conform to the norms to be accepted and will be less likely to use drugs. This shows the contextual effects of religion whereby, irrespective of individual religiosity, individuals are still likely to be impacted by religion if they are in a strong religious environment.

Religion is, thus, an important social institution that has a strong norm setting influence on societal members through its norms and religious teachings that set behavior expectations (Parboteeah et al. 2009a). Throughout centuries, religions have explicated (through scriptures and the practice of religions) and reinforced specific principles through prescriptions regarding the moral life. Whether someone is religious or not, an individual residing in more religious societies is more likely to be impacted by wide ranging religious influences as they interact with many others who may be more religious. A religion "acts as a synthesizer of national or societal meaning systems” (Drakopoulou Dodd \& Seaman 1998: 72).

Although as Galbraith and Galbraith (2007: 190) mention, "all religious traditions have addressed the connection between work (including entrepreneurship) and religion," Dana (2009) notes that different religions value entrepreneurship differently. For instance, the Buddhist religion's focus on elimination of unsatisfied desires as the path to salvation is often 
seen as having a restraining effect on entrepreneurship. According to Buddhist doctrines, living the religious life means finding ways to eliminate the desire to satisfy material needs. Islam's prohibition of interest payments also represents a barrier to capital and therefore constrains entrepreneurship (Dana 2009).

Although not all religions value entrepreneurship similarly, one religion that has been shown to be related positively to entrepreneurship is Christianity. We therefore focus our study on countries that are primarily Christians for several reasons. First, Weber's Protestant work ethic is often seen as the original work whereby religion viewed entrepreneurship activity as the moral way of life. In fact, the small business can be regarded as the embodiment of such important principles (Drakopoulou Dodd \& Seaman 1998). It seems therefore plausible to expect that Christianity is positively related to entrepreneurship. Second, there is evidence that Christian societies are more likely to provide a supportive atmosphere for entrepreneurship. As Galbraith and Galbraith (2007: 191) note, within the Christian tradition, "there is a clear moral component of entrepreneurial effort" and an “already established and strongly positive moral attitude toward work, trade, value creation, innovation and entrepreneurial activity". Furthermore, as Drakopoulou Dodd and Seaman (1998: 72) argue, not all religions may necessarily strengthen the "munificence of the environment of religion in a given society". Third, combining religions in a single study may commingle confounding factors that prevent us from assessing accurately the link between religion and entrepreneurship. We therefore believe that this focus on Christian societies allows us to more accurately assess the link between religion and entrepreneurship.

How is Christianity related to the desire to be an entrepreneur? There seems to be a number of mechanisms that explain such a relationship. First, as Drakopoulou Dodd and Seaman (1998) argue, religion can often provide the environmental munificence supportive of entrepreneurship. Because of its emphasis on hard work and entrepreneurship, Christianity provides a legitimizing and supportive atmosphere for entrepreneurship. Second, Galbraith 
and Galbraith (2007) suggest that the link between religion and entrepreneurship also occurs through economic growth. Because countries with more religious individuals have been found to typically correlate with economic attitudes conducive to highest per capita income and growth, one manifestation of such positive attitudes towards growth is through entrepreneurship.

We therefore argue that religions will have contextual effects on individuals in more religious environments. Irrespective of their individual religiosity, individuals in more religious societies are more likely to interact with others who are religious. As we argue later, in such societies, residents are more likely to be exposed to and imparted by religious values conducive to entrepreneurship. Thus, whether these individuals are practicing Christians or not, they are also more likely to place higher value on entrepreneurship.

In considering the link between Christianity and entrepreneurship, we use a conceptualization of religious aspects developed and validated by Parboteeah et al. (2009a) based on Kostova's (1999) country institutional profile. It specifies that religions have three contextual elements, namely a cognitive aspect, a normative aspect and a regulative aspect. Disentangling these three key dimensions of religion allows us to study religion's effects on entrepreneurship in a comprehensive and fine-grained way. Thus, our approach contrasts with other studies that consider only single dimensions of religiosity (Drakopoulou Dodd \& Seaman 1998) or have no theoretical basis for the selection of religion variables.

\section{Differential impacts of a country's religious aspects}

\section{Cognitive aspect}

The cognitive aspect refers to the 'knowledge' aspect of religion (Parboteeah et al. 2009a). It reflects expectations regarding religious beliefs as evident in statements such as belief in the 
importance of God or mere belief in the existence of God. We argue that it is positively related to entrepreneurial activity. Entrepreneurship is associated with hard work and an uncertain outcome. Prior entrepreneurship research has shown that entrepreneurs on average earn less and work harder than individuals in paid-employment (Hamilton 2000). Moreover, the distribution of entrepreneurial income is highly skewed (Åstebro 2003; Hamilton 2000). To start a new venture, a tolerance for hard work and the ability to deal with situations of high uncertainty is needed.

Christian countries with high levels of the cognitive aspect are more likely to have environments conducive to entrepreneurship. In such societies, the environment is likely to provide a supportive atmosphere for entrepreneurship by emphasizing values and norms such as hard work and thrift and thus a clear moral component of entrepreneurial effort (Galbraith \& Galbraith 2007). Belief in the existence of God is more likely to provide such individuals with the means to confront the uncertainties inherent in entrepreneurship in contrast to individuals who reside in less religious environments. As adherents live with the set of principles that a strong Christian environment provides, they are more likely to be influenced by the need to be entrepreneurial inherent in their faith. Cornwall and Naughton (2003) emphasize the importance of seeing entrepreneurship as more than just a means of income, thereby pointing to another potential link between the cognitive environment and entrepreneurship. Indeed, research suggests that entrepreneurial success can also have moral dimensions whereby entrepreneurship is seen as a source of personal fulfillment or the ability to help others (Alstete 2008). We believe that this aspect of entrepreneurship should also provide strong arguments to expect the cognitive dimension of religion to be positively related to entrepreneurship. Societies with strong cognitive environments are more likely to encourage adherents to see the moral aspects of entrepreneurship and thereby engage in entrepreneurship. Entrepreneurship may thus become the means for individuals to fulfill their religious values. 
From a contextual effects perspective, whether someone is religious or not, an individual residing in a more religious environment is more likely to interact with others sharing the values emanating from stronger religion (Stark \& Bainbridge, 1996). As mentioned earlier, such values include aspects such as hard work, thrift and better ability to deal with uncertainty. Given that such values are strongly related to entrepreneurial effort, it is therefore more likely that those individuals residing in stronger religious environment are exposed to values conducive to entrepreneurial activity. They are therefore more likely to be directly or indirectly impacted by such values compared to someone who resides in a less religious environment. We therefore hypothesize:

Hypothesis 1a The cognitive aspect of religion is positively related to entrepreneurial activity.

Normative aspect

The normative aspect refers to the context of "social norms, values, beliefs and assumptions that are socially shared and carried by individuals" (Kostova 1999: 180). It reflects the preferred way of how things should get done when individuals are faced with decisions that have religious implications. While the cognitive aspect describes the knowledge and beliefs individuals have regarding religion, the normative aspect is often reflected in their religious practice indicating the value they place on religions (Parboteeah et al. 2009a). The more societies have high levels of the normative aspect, the more likely it is that the residents will participate in religious activities such as such as attending church, praying or even making financial donations to their church.

The normative aspect is, as we argue, positively related to entrepreneurial activity. This is because it exposes individuals with the strong values inherent in supporting 
entrepreneurship within the country. We expect that the daily interactions with others who value entrepreneurship and exposure to rituals and practice that encourage entrepreneurship inherent in strong Christian environments will create interest in an entrepreneurial career. Furthermore, to remain in good standing vis-à-vis other societal members, individuals within societies with stronger normative aspects are more likely to conform to such requirements by being entrepreneur. This is less likely to occur in societies where weaker normative religious environments imply that societal members are less likely to be exposed to expectations inherent in the values and norms supportive of entrepreneurship.

A second mechanism whereby the normative aspect is likely related to entrepreneurship is through social networks. It is well established that personal and professional networks are critical to potential entrepreneurs (Aldrich \& Zimmer 1986; De Carolis \& Saparito 2006; Ozgen \& Baron 2007). Individuals who reside in stronger normative religious environments are more likely to have access to a personal network of individuals who value entrepreneurship as the means to practice the Christian faith. Mobilizing resources via networks is facilitated in highly religious environments, if Christian religion provides a code of conduct for human interactions and, more specifically, doing business. This reduces uncertainty and fear of moral hazards that can keep individuals from providing resources for entrepreneurs (Stuart \& Sorenson 2007). Thus, at a very basic level, daily interactions with practicing members will impart the importance of entrepreneurship to others.

Moreover, recent research suggests that religion, specifically in predominantly Christian societies, also engenders significant economic activity (Pearce Ii et al. 2010). Churches and religious congregations have to operate as businesses if they are to survive. As such, religious societies may provide its members with specific entrepreneurial advice to succeed. Even for minority religions, a recent study shows that the Korean ethnic church acts as a small business incubator for their members (Choi 2010). Church membership was also found to mitigate the risk of bankruptcy through a safety net mechanism (Hansen \& Hansen 2008). Religion can 
thus provide the social capital and personal network from which adherents can gain access to entrepreneurial advice.

Altogether, the above arguments provide the basis to expect contextual effects of the normative aspects of religion on entrepreneurial activity. Specifically, individuals in stronger normative environments are more likely to be exposed to rituals and values supportive of entrepreneurship through social interactions with individuals sharing such values.

Furthermore, the religious environment can also have an indirect influence through social control and support (Stark \& Bainbridge, 1996). Even if someone is not necessarily religious, she is more likely to get exposed to a social network conducive to entrepreneurship in stronger normative religious environments. We therefore hypothesize:

Hypothesis 1b The normative aspect of religion is positively related to entrepreneurial activity.

Regulative aspect

The regulative aspect of religion refers to the rules and regulation dimension of religiosity (Parboteeah et al. 2009a). In some societies, religion is strongly influenced by the state or the government (Barro \& McCleary 2005). In such societies, the government may appoint or approve of religious leaders, provide subsidies through payments to church employees or even collect taxes dedicated to church uses. For example, many Scandinavian countries have established state churches that are heavily influenced by the government (Barro \& McCleary 2005)

We propose that, unlike the other two dimensions of religion, the regulative aspect is negatively related to entrepreneurial activity. Our arguments are based on the premise that the regulative aspect is typically represented by state religions and represents an external aspect 
of the manifestation of the divine. As Barro and McCleary (2005) argue, the presence of state religions typically interferes with the personal nature of religion through the appointment of religious leaders and collection of taxes to support religious institutions. This government administered aspect of religion likely clashes with the spiritual nature of religion thus resulting in a "spiritual wasteland" (Iannaccone et al. 1997: 354). Such assertions are empirically validated by studies that find that the presence of strong state regulation of religion is often linked with low levels of religious participation. As such, we believe that the impersonal nature of the regulative nature of religion is likely to negatively relate to entrepreneurial activity. The presence of state religions is likely to imply the presence of rules and regulations that interfere with the entrepreneurial driving aspects associated with the other more personal forms of religion.

Similar to our arguments leading to the previous two hypotheses, we propose that the contextual religious environment will be related to entrepreneurial behavior. In societies with strong regulative religious environments, residents are more likely to be exposed to influences that lessen the divine nature of religion. As such, individuals in such societies are more likely to interact with others who may not share a strong preference for entrepreneurial activity. We therefore propose:

Hypothesis 1c The regulative aspect of religion is negatively related to entrepreneurial activity.

\section{The role of a country's knowledge investments}

Our above arguments revolve around the notion that individuals are more likely to pursue entrepreneurial careers in highly religious environments because religion shapes an entrepreneurship-friendly atmosphere by valuing hard work and thrift, by helping to cope with 
the burden of uncertainty, and by providing access to critical resources and information.

Interestingly, however, countries with a similar religious profile vary in the extent of entrepreneurial activity (Kelley et al. 2012). One explanation for this empirical paradox is, as we suggest below, provided by prior research on knowledge investment and spillovers (Acs et al. 2009; Audretsch \& Keilbach 2007; Audretsch \& Lehmann 2005; Braunerhjelm et al. 2010). Based on this literature, we propose important contingency effects of a country's level of knowledge investments. In other words, religious aspects may matter more for entrepreneurial activity in countries that have abundant knowledge investments for two reasons.

First, prior research suggests that knowledge investments lead to knowledge spillovers and thus the evolution of entrepreneurial opportunities (Acs et al. 2009; Braunerhjelm et al. 2010). This argument is empirically supported by Audretsch and Lehmann (2005), among others, who find that regions with greater investments in knowledge also have higher start-up rates. More specifically, individuals in more religious countries are, as we propose above, more willing and possibly more able to exploit given entrepreneurial opportunities. While motivation and ability may constitute a necessary condition for entrepreneurial behavior, the existence of entrepreneurial opportunities may provide a sufficient condition (Shane \& Venkataraman 2000). In other words, the effect of Christianity on entrepreneurship is contingent upon a country's level of knowledge investments because such knowledge investments are positively related to the supply with entrepreneurial opportunities (Acs et al. 2009; Braunerhjelm et al. 2010; Lucas Jr 1988; Romer 1990). Those individuals in more religious societies who are more predisposed to entrepreneurship are more likely to act on those impulses as the knowledge environment provides the necessary input to make the preference for entrepreneurship a reality.

Second, religion has a strong positive effect on entrepreneurial activity in countries where entrepreneurship is seen as a productive force for society (Baumol 1990) and 
entrepreneurial success is admired. This is likely to be the case in knowledge-driven economies which are open towards science and technological progress. Entrepreneurs turn knowledge into innovation and act as agents of technological change and societal progress (Acs et al. 2009; Block et al. 2013b; Brouwer 2002). A positive public image of entrepreneurship leads to a social environment where religious beliefs can stimulate entrepreneurial activity (Van De Ven 1993). It is the combination of religious beliefs and openness towards science and technological progress that leads to entrepreneurial activity.

A similar point is made by Weber (1930: 119) who suggested that the full economic effect of great religious movements tended to set in after religious enthusiasm cooled down and passed over into a more utilitarian mindset. Religious individuals then started to adopt more worldly principles, alongside religious principles, and to "make the most of both worlds" (ibid). Thus, although two countries have similar religious profiles, they often differ in their acceptance of new values, technologies and knowledge, as also reflected in state funding of research and knowledge investments. For instance, Poland and the United States score similarly on the normative aspect, whereas their openness towards genetic engineering and its commercial exploitation differs substantially (TNS Opinion \& Social 2010). We therefore propose that the relationship between religious aspects and entrepreneurial activity will be contingent upon a country's investments into knowledge. Stated more formally:

Hypothesis 2a The level of a country's knowledge investments will strengthen the relationship between the cognitive aspect of religion and entrepreneurial activity.

Hypothesis $\mathbf{2 b}$ The level of a country's knowledge investments will strengthen the relationship between the normative aspect of religion and entrepreneurial activity. 
Hypothesis 2c The level of a country's knowledge investments will weaken the relationship between the regulative aspect of religion and entrepreneurial activity.

\section{Methods}

Sample and procedure

All individual-level data came from the Flash Eurobarometer Survey No. 283 on Entrepreneurship (hereafter Flash EB) gathered by The Gallup Organization (2010). ${ }^{1}$ The survey covers 36 countries, including the 27 EU member states, five other European countries (Croatia, Iceland, Norway, Switzerland, and Turkey), the US, and three Asian countries (China, Japan, and South Korea). A total of 26,168 randomly selected respondents were interviewed mainly via telephone (December 10, 2009, to January 16, 2010). ${ }^{2}$ The target sample size for each country amounts to a maximum of 1,000 respondents. The dataset is particularly beneficial for the purpose of our study as it is representative of the national population aged 15 years and older (Gallup Organization 2010) and comprises countries with sufficient variance in country-level variables - a necessary condition for our research.

We excluded seven countries with missing data for religion variables (Austria, China, Cyprus, Norway, Portugal, South Korea, and Switzerland) and the only two non-Christian countries (Japan and Turkey). Moreover, we retained individuals who were at working age (16 to 65 years old) and who stated being either in wage-employment or in self-employment. This led to our final sample of 9,266 individuals in 27 countries. The average respondent was female $(55 \%), 44$ years old $(\mathrm{sd}=10.79)$ and had 15 years of schooling $(\mathrm{sd}=4.36)$. The profile of our sample is therefore comparable to data from the well-established Global

\footnotetext{
${ }^{1}$ Block et al. (2013a) used this dataset to study the decision to take over a business versus starting a new one.

${ }^{2}$ About one third of the interviews in Bulgaria, the Czech Republic, Estonia, Hungary, Latvia, Lithuania, Poland, Romania, and Slovakia were conducted face to face.
} 
Entrepreneurship Monitor used in various studies (e.g., Anokhin \& Schulze 2009; Kwon \& Arenius 2010; McMullen et al. 2008). ${ }^{3}$ Table 1 provides further details on our sample.

Please insert Table 1 about here

Measures

Dependent variable

The EB survey collected information on entrepreneurial activity through one question "As far as your current occupation is concerned, would you say you are self-employed, in paid employment or would you say you are without a professional activity?" After the respondent had stated being self-employed, wage-employed, or without professional activity, the interviewer requested further details to check whether the respondent's self-categorization was consistent with definitions provided in the EB survey. Self-employment included professions, such as architects and owner-managers of a company, whereas wageemployment compromised any white- or blue-collar activity. The third category without "professional activity" (i.e., students, retired individuals, and unemployed) was disregarded in our main analysis. The responses were dummy-coded ( 1 for being self-employed, 0 for being wage-employed) to obtain our final measure of entrepreneurial activity. The measure is comparable to an established measure used in the Global Entrepreneurship Monitor (Flash EB: mean $=0.14, \mathrm{sd}=0.34 ;$ GEM: mean $=0.15, \mathrm{sd}=0.36)$.

\footnotetext{
${ }^{3}$ Both samples were similar regarding respondent age (Flash EB: mean $=44.12$, sd = 10.79, GEM 2006: mean = 42.22, sd = 12.59). While the Flash EB comprised a higher share of females at working age (55\%) than GEM (44\%), both datasets were close to the equal female-male ratio estimated by the World Factbook (Central Intelligence Agency 2012) for the countries in our sample.
} 
Data for all religious components came from the World Values Survey (WVS, World Values Study Group 2011) as reported in Parboteeah et al. (2009a). The project followed established procedures of translation-back translation to ensure a maximal cross-cultural equivalence of the measures. WVS data has been used and validated in extant spirituality research (e.g., Parboteeah et al. 2008; Parboteeah et al. 2009a; Parboteeah et al. 2009b), thereby contributing to our understanding of religion both in terms of comparison between countries as well as longitudinal comparison within countries (Davie 2007).

Table 1 above presents specific scores for the religion measures in this study. The measures for the cognitive and normative aspects come from aggregation of individual measures - a practice consistent with the literature as discussed by Lim \& McGregor (2012: 749) in that "religious context is often operationalized by aggregating personal religious characteristics, most commonly religious affiliation or frequency of church attendance." This approach is consistent with the application of the contextual effects approach where such aggregation represents religious moral communities that are group properties (Stark \& Bainbridge 1996).

Consistent with De Jong et al. (1976) and Kelley and De Graaf (1997), the cognitive aspect is measured with five items representing belief in religion. These items captured the degree to which individuals believe in God, an after-life, hell and heaven. To aggregate individual-level WVS data, the percentage of individuals per country who responded positively to the dummy-coded beliefs $(1=$ yes, $0=$ no $)$, was combined with a 10 -point scale. The five items were then standardized and averaged to create the cognitive component. The measure is reliable at a country-level alpha of 0.97 .

The normative aspect was measured with two items reflecting the strength of the normative environment (norms to pray and attend church). The more individuals value 
religion, the more they are involved in private prayer and public church attendance (Myers 2000). Such practice is, therefore, seen as an appropriate indicator how much value individuals place on religion. Using WVS data, we computed the country percentage of people stating that (1) they prayed and (2) attended church at least once a week. The construct provides, as Parboteeah et al. (2008) discuss, a valid measure for the normative or behavioral aspect of religion. It is reliable at a country-level alpha of 0.90 .

The regulative aspect was measured with a dummy variable $(1=$ state religion, $0=$ no state religion) which reflects the regulative environment as the state may potentially appoint church leaders or provide subsidies to religious authorities (Barro \& McCleary 2005).

Knowledge investments refer to the efforts made in a country to promote technological innovations and acquire novel knowledge (Griliches 1990; Jaffe et al. 1993). Such tacit knowledge can yield competitive advantage, thereby providing a good seedbed for entrepreneurial activity (Barney 1991). We use the extent to which organizations within a country invest in research and development (R\&D) as a proxy of knowledge accumulation. More specifically, we relied on four items retrieved from different, widely used sources. Two items, R\&D expenditures in percentage of GDP and number of researchers in R\&D per million people, came from the World Development Indicators (World Bank 2011). The other items, company spending on R\&D and capacity for innovation, were taken from the Global Competitiveness Report (World Economic Forum 2010). They are based on experts' opinions on the questions "To what extent do companies in your country spend on research and development (R\&D)?” (1 = “do not spend on R\&D” to 7 = "spend heavily on R\&D”) and "In your country, how do companies obtain technology?" (1 = “exclusively from licensing or imitating foreign companies" to 7 = "by conducting formal research and pioneering their own new products and processes"). The average of the standardized items for the years 2004 to 2010 yielded our final measure of knowledge investments. Consistent with the general 
expectation that $R \& D$ inputs eventually lead to $R \& D$ outputs, the measure highly correlates with the number of patents $(r=.84, p<.001)$. It is reliable at a country-level alpha of 0.97 .

\section{Control variables}

To tease out the effect of our predictor variables, we considered several critical control variables. Age is often associated with a decreased likelihood to opt for entrepreneurship, as individual opportunity costs increase with age (Davidsson \& Honig 2003; Lévesque \& Minniti 2006). Extant research has revealed that men are more likely than women to start and operate their own business (Brush 1992; Verheul et al. 2006). Gender was considered with a dummy variable for being male $(1=$ male, $0=$ female $)$. Formal education can facilitate identifying and successfully exploiting entrepreneurial opportunities, thereby increasing the payoff from entrepreneurship (Davidsson \& Honig 2003). Education level was measured as age when completed full-time education. Individuals with entrepreneurial role models are more likely to become entrepreneurs as they are socialized into an entrepreneurial career (Scherer et al. 1989) or inherit critical entrepreneurial knowledge (Tervo 2006). Role model effects were considered with two dummy variables, self-employed mother and a self-employed father, coded 1 if the respective parent is or has been self-employed.

Several personality traits are associated with a higher tendency to start a business (Rauch \& Frese 2007). Entrepreneurs typically take more risks than others as they face less structured and more uncertain problems and bear the ultimate responsibility for their decisions (Stewart Jr. \& Roth 2001). Risk tolerance was measured with one item "In general, I am willing to take risks" on - like the other traits - a 4-point Likert-scale ( 1 = "strongly disagree" to 4 = "strongly agree"). Self-confidence can give the necessary persistence an entrepreneur needs to pursue goals in the face of high uncertainty. The variable was measured with the item "Generally, when facing difficult tasks, I am certain that I will accomplish them". Individuals 
feeling able to control outcomes tend to exert more effort towards these outcomes which helps in starting a business (Rauch \& Frese 2007). Internal locus of control was captured with the item "My life is determined by my own action, not by others or by chance". Highly creative individuals are more likely to discover entrepreneurial opportunities - a necessary condition to become an entrepreneur (Lee \& Wong 2004). Inventiveness was captured with the item "I am an inventive person who has ideas". Competition oriented individuals tend to self-select into entrepreneurial careers as this occupation provides concrete feedback regarding own performance (Collins et al. 2004). Desire for competition was measured with the item "I like situations in which I compete with others". Optimism is another trait that has been associated with entrepreneurial activity (Rauch \& Frese 2007) and was measured with one item "I am optimistic about my future". Entrepreneurship education can sensitize and prepare for entrepreneurial careers (Martin et al. 2013). We controlled for the perceived quality of entrepreneurship education by a reflective measure with four items ("My school education helped me to develop my sense of initiative - a sort of entrepreneurial attitude", "My school education helped me to better understand the role of entrepreneurs in society", "My school education made me interested to become an entrepreneur", "My school education gave me skills and know-how that enable me to run a business", $\alpha=.82$ ). Finally, we controlled for variance in national wealth in terms of GDP per capita in purchasing power standards in millions of international dollars as the average of the years 2004-2010. The data were obtained from the World Economic Outlook database provided by the International Monetary Fund (2010).

\section{Analysis}

To test our cross-level hypotheses, we employed hierarchical linear modeling (HLM; Raudenbush \& Bryk 2002) with restricted maximum likelihood estimates. HLM examines 
each variable at the appropriate level of analysis and considers the partial interdependence between individuals within the same group. The method estimates parameters and standard errors by weighting group-level sample size by reliabilities at the individual-level (level 1), for the dependent variables within each group (level 2). This allows overcoming the statistical shortcomings, in particular aggregation or disaggregation bias, of traditional approaches to analyze nested data (Hofmann 1997). While the estimates closely correspond to OLS, HLM reduces the deflation of standard errors that typically plague OLS approaches. Since our hypotheses propose main effects of level 2 variables on level 1 outcomes (entrepreneurial activity), we used intercepts-as-outcomes models. All level 1 predictors were centered around their group mean to mitigate multi-collinearity and to render the intercept more interpretable. Consequently, the intercept represents the occupational status of a respondent with a group average score on all individual-level predictors (Hofmann 1997). However, using uncentered data yielded the same pattern of results.

To account for the Bernoulli distribution of our outcome, we specified hierarchical generalized linear models (HGLM). As in regular logistic regression, the individual-level estimates do not refer to levels of outcomes but refer to the natural logarithm of the likelihood that an outcome will take a value of 1 (for being an entrepreneur) rather than a value of 0 (for being wage-employed). In contrast, the country-level parameters are interpreted in a way that is similar to that employed in normal regression because the intercepts and slopes from the individual-level model are continuous and normally distributed. 


\section{Results}

Main findings

Table 1 provides more details on our sample. Table 2 documents the descriptive statistics and correlation matrix. Tables 3 and 4 report the regression results. Computations of the variance inflation factor (VIF) reveal no serious multicollinearity problems (VIF $<1.31$ ).

Please insert Tables 2 - 4 about here

Model 2 in Table 2 tests our main effect hypotheses for the religious aspects. Only the relationship between the cognitive aspect and entrepreneurial activity was weakly significant but no significant relationships were found for the normative aspect and regulative aspect. Hypotheses 1a to 1c were therefore not supported. Moreover, Models 4 and 6 present the results for our hypotheses for the contingency effect of a country's level of knowledge investments. As predicted in Hypothesis 2a, the level of such investments significantly impacts the relationship between the cognitive aspect and entrepreneurial activity. To advance further interpretation, we plotted the interaction effect following recommendations in the extant literature (Hoetker 2007; Norton et al. 2004). ${ }^{4}$

Please insert Figure 1 about here

\footnotetext{
${ }^{4}$ The interpretation of interactions in logit models differs substantially from regular OLS models. In non-linear regression, the effect of the interaction is a function of the interaction coefficient and - unlike in OLS regression - of the coefficient of each interacted variable and of the values of all covariates. The magnitude and sign of an interaction can thus vary across observations. The coefficient alone is an insufficient basis for conclusions about the interaction's sign and significance. The magnitude and even sign of the effect can differ across observations. Moreover, the statistical significance of the interaction cannot be determined from the regression output, but is conditional on the covariates. Ignoring these differences, many researchers in the fields of, for instance, strategic management (Hoetker 2007) and economics (Norton et al. 2004) have misinterpreted interactions in logit models.
} 
Hypothesis $2 \mathrm{~b}$ was also supported as the interaction effect of the normative aspect with knowledge investments was significant and positive - an impression supported by the interaction plots displayed in Figure 2. No significant interactive effect of the regulative aspect was found, disconfirming Hypothesis 2c. Together, the findings for Hypotheses $2 \mathrm{a}$ and $2 \mathrm{~b}$ suggest that the effect of the cognitive and normative aspects is stronger in more knowledge-driven countries.

Please insert Figure 2 about here

The role of culture

Prior research indicates that national culture can trigger entrepreneurial activity, although to date no consensus about the nature of this effect has emerged (Hayton et al. 2002; Hayton \& Cacciotti 2013). Some scholars propose a direct effect of culture (e.g., Davidsson 1995; Uhlaner \& Thurik 2007; Stephan \& Uhlaner 2010). Other scholars suggest mediating effects between aspects of culture and religion in shaping entrepreneurship (Drakopoulou Dodd \& Gotsis 2007). Another group posits that it is the interplay of culture with institutions, including religion, what fosters entrepreneurship within a society (e.g., Cullen et al. forthcoming; Li \& Zahra 2012; Pinillos \& Reyes 2011).

We tested all these possibilities drawing on Hofstede's (1980) four cultural dimensions power distance, individualism, masculinity, and uncertainty avoidance. Correlation analyses pointed to few links between culture and religion, suggesting that power distance was negatively correlated with the regulative aspect $(r=-.49, p<.01)$ and masculinity weakly correlated with the cognitive $(r=.34, p<.10)$ and normative dimensions $(r=.37, p<.10)$. 
Moreover, we added cultural dimensions as control variables. Although some dimensions, such as masculinity and power distance, had a significant effect, the pattern of our original results did not change. Moreover, analyses suggested by Barron \& Kenny (1986) could not reveal mediating relationships between religion and culture, given the non-significant relationships of religious aspects with entrepreneurial activity. We could also find no evidence for a mediated moderation (Muller et al. 2005), where culture mediates the moderation effect of religious dimensions with a country's knowledge investments on entrepreneurial activity. Finally, we reran the above analyses using four cultural values suggested by the GLOBE study (House et al. 2004), including power distance, institutional collectivism, assertiveness orientation and uncertainty avoidance. Only uncertainty avoidance was weakly correlated with the cognitive dimension $(r=.35, p<.10)$ and none of these variables was significant in our regressions. The results did not point to mediation effects or mediated moderation effects. Taken together, these findings suggest a direct impact of some cultural aspects, but do not point to the existence of more complex relationships between culture and religious dimensions, including mediation effects or even mediated moderation effects.

Other robustness checks

To confirm the robustness of our results, we conducted several additional analyses. First, we reran the estimations using alternative country-level control variables, including unemployment rate, availability of bank loans, availability of venture capital, cost of business start-up procedures, number of new businesses registered, average years of tertiary schooling, and control of corruption. The pattern of our results did not change. Second, the exclusion of unemployed people can create a potential biasing problem. We therefore added unemployed respondents to our sample and estimated the likelihood of being self-employed vis-à-vis being wage-employed or unemployed. This led to no notable changes of our initial findings. Third, 
given the high correlation between the cognitive and normative aspects, we analyzed both aspects separately. Again, our main results remained stable. Finally, in addition to testing our theory with knowledge investments as a proxy for innovation inputs, we reran our regressions using patents as a proxy of innovation outputs. Patents were measured as the number of utility patents, i.e. patents for inventions, granted in 2008 per million population (World Economic Forum 2010). This produced the same pattern of results as for our innovation input measure.

\section{Discussion and implications}

Since Weber's ([1922] 1978) seminal work on Protestant work ethics, the impact of religion and religious institutions on economic activity has had a long standing tradition in research. A more recent stream of empirical research has furthered our understanding of how the faith of an individual, such as Greek Orthodoxy (Gotsis \& Kortezi 2009), Buddhism (Valliere 2008), and Islam (Essers \& Benschop 2009), affects his or her entrepreneurial activity and thinking. However, there has been relatively little systematic development, both theoretical and empirical, that adopts a contextual perspective by linking country religious profiles to entrepreneurship, while also considering a country’s investments into knowledge and technology as a critical contingency factor. Research progress along these lines has been hindered by substantial methodological (Hofmann 1997) and theoretical barriers (Parboteeah et al. 2009a) in the past. In addressing this important lacuna, our study explored differential effects of a country's religious profile on individual entrepreneurial activity and the contingent effect of a country's investments into knowledge in this milieu.

The key insight of this study is that a Christian environment plays an important role for entrepreneurship in countries investing in and producing considerable stocks of innovative knowledge. As proposed in Hypotheses $2 \mathrm{a}$ and $2 \mathrm{~b}$, the effects of the cognitive and normative aspects on entrepreneurial activity were contingent upon a country's knowledge investments. 
This finding is consistent with the notion that religion can shape the motivation to pursue entrepreneurial careers (a necessary condition for entrepreneurship) if technological innovation in a country creates entrepreneurial opportunities (a sufficient condition for entrepreneurship) that motivated individuals can discover, develop, and exploit. Thus, our understanding of how a country's religious profile influences individual entrepreneurial activity seems to require considering a country's investments into knowledge and technology.

Theoretical contributions

In addressing several important gaps, our study extends the literature on multiple fronts. First, by showing the contingent effects of the knowledge investments of a country, the study contributes to a more nuanced understanding of the religion-entrepreneurship link. Already Weber (1930: 119) has proposed that entrepreneurial activity is more likely if religious enthusiasm blends with a utilitarian mindset. Our study extends this notion, theoretically and empirically, by suggesting that entrepreneurial activity is more likely in countries where religion and technological innovation coincide. Moreover, in combining logic from the literatures on religion and knowledge spillovers, our paper brings together two streams of literature which so far have been largely unconnected: Recent works of Acs et al. (2009) and Audretsch and Lehmann (2005) show that knowledge creates entrepreneurship, whereas Choi (2010), Drakopoulou Dodd and Seaman (1998), Furnham and Koritsas (1990) and Galbraith and Galbraith (2007) argue that the religious environment explains entrepreneurship. Our paper shows that the combination of knowledge investments and religious values has the strongest effect.

Second, our findings add to the field of cross-country entrepreneurship research where religion has not been systematically examined. It is recognized that religions have important implications within the work context (Parboteeah et al. 2009a). However, most cross-country 
examinations of entrepreneurial activity have instead focused on culture or institutions (Begley \& Wee-Liang 2001; Bowen \& De Clercq 2008; Thomas 2000). By examining how and when the different aspects of religion are related to entrepreneurship, we address the shortcomings of previous studies (Choi 2010; Drakopoulou Dodd \& Seaman 1998). Our study also recognizes the importance of religion in addressing cross-cultural differences beyond cultural dimensions (Hofstede 1980; House et al. 2004).

Finally, we also acknowledge the cross-level nature of the religious environment. By emphasizing the contextual nature of the religious environment, we show that religion can have an impact on preference for entrepreneurial careers irrespective of individual characteristics, if embedded in a country focusing on knowledge investments. Prior studies on individual religiosity have implicitly assumed that the effect of religion is restricted to adherents of a certain faith. Our study relaxes this assumption by conceptualizing religion as a country-level influence that affects adherents and non-adherents. The findings seem to support Kelley and De Graaf's (1997) suggestion that religion can have an impact on individuals whether they consider themselves religious or not. The mere exposure and interaction of individuals within more religious societies likely impact non-adherents.

Ethical implications

Our finding that countries with strong religious profiles and intensive investments into knowledge are conducive to entrepreneurial activity warrants further discussion from an ethical perspective. Our arguments revolved around the notion that religion shapes an environment, in which hard work is valued, uncertainty easier to bear, and critical resources and information more readily available, making entrepreneurial activity more likely. But does the influence of the religious context stop here or does it further affect business activity? In particular, Christian religion provides a value system or code of conduct that helps to 
distinguish right from wrong behavior. This raises the important question of whether companies emerging in more religious environments are also more likely to adhere to Christian values and act in a socially responsible manner. Related research by Mascarenhas (1995) indicates that religiousness shapes fundamental beliefs and values, leading executives to consider their social responsibility. Similarly, Ramasamy et al. (2010) find that religiosity, but also social desirability can drive consumers' support for corporate social responsibility. Overall, this research seems to support the notion of more social responsible entrepreneurship in more religious environments but further empirical evidence is required to substantiate this suggestion.

In our study, religion has a positive connotation: It provides a seedbed for entrepreneurship in some countries and thus for economic welfare and growth (Pinillos \& Reyes 2011). However, a balanced ethical view requires that we also acknowledge the potential negative effects of religion. A recent review of studies of religion by Chan-Serafin, Brief \& George (2013: 1585) laments that most religion studies "seems to imply that religion is a benign and positive force." Our study also adopts this approach. But it is important to note that most of the countries we consider in this study are mostly with fairly strong institutions. However, religion is not always a positive force. Religion can sometimes be negative in that strong environments can result in religious fundamentalism, a strong predictor of intolerance towards women, ethnic minorities, and gay and lesbians (Hunsberger \& Jackson 2005). Furthermore, strong religious climates within organizations can also lead to prejudice against those who are not religious (Chan-Serafin et al. 2013). Thus, while our findings do point to the positive aspects of religion, a balanced view of the ethics of such research is necessary.

From an ethical standpoint, our findings also have important implications for multinationals. Specifically, while it has been acknowledged that multinationals often ignore religion in their global operations, our results show that there are potential benefits operating 
in more religious environments. The enhancing effects of the country's knowledge

investments suggests that companies may potentially encourage entrepreneurial behaviors by creating an environment that supports entrepreneurship in more religious environments. Thus, while we do not explicitly test organizational environments supportive of entrepreneurship, our results suggest such possibilities.

Limitations and future research

Our study's limitations constitute interesting areas for future research. First, we assumed that all forms of Christianity are related positively to entrepreneurship. We do acknowledge, for instance, that Weber's Protestant work ethics was developed based on Protestantism and may not necessarily apply to Catholics (Weber, 1930). However, our arguments were centered mostly on the notion that Christianity, in comparison to other religions, tends to be more strongly associated with entrepreneurship. Second, our sample consists of Christian countries. The results are thus conditional and mostly generalizable to this context. Prior research by Parboteeah et al. (2009a) has shown that the Protestant work ethic is not necessarily limited to Protestant societies. By extending the study to other religions and countries, it will be possible to determine whether the effects of religion on entrepreneurship hold for all religions. Third, we use data from the Flash Eurobarometer Survey that relies on single-item measures of psychological traits. While this precludes testing reliability, prior research has demonstrated that single-item measures have sufficient estimated reliability (Wanous \& Reichers 1996) and do not significantly differ in predictive validity from multiple-item measures (Bergkvist \& Rossiter 2007). However, the results for our control variables should be interpreted in that light. Future research could corroborate our findings by using measures with proven reliability. Fourth, we examined a country's knowledge investment as a contingency of the religion-entrepreneurship link. Future research should study other potential moderators such 
as the availability of venture capital or entrepreneurial talent. Furthermore, country-level influences might also foster entrepreneurial activity by reinforcing individual traits. Future research might further explore this interesting possibility which is beyond the scope of this study. Fifth, while our findings were robust to controlling for cultural influences, it lies outside the scope of this study to comprehensively explore the complex interplay between culture and religion in shaping entrepreneurship — another interesting avenue for future research. Finally, our results for the various aspects of religion need to be explored in other contexts. Specifically, as an example, it is possible that the non-personal nature of the regulative aspect may have influence on more external aspects of entrepreneurship such a firm level innovation. We hope that future research will investigate such relationships to determine what variables religion has direct influences on.

\section{Conclusions}

In this paper, we addressed an important gap in the literature by examining the religious aspects of a country and their relationships with individuals' entrepreneurial activity. Furthermore, we argued that the knowledge investments in society are important contextual influences that moderate the relationship between religious aspects and entrepreneurial activity. Empirical verification using a representative sample of individuals from 27 Christian countries support our contention that knowledge investments in a society matter in terms of providing a context that motivates and enables societal members to pursue entrepreneurial careers. Such findings provide a more refined understanding of the historical link between religion and entrepreneurship. We hope that the study will spur more refined look at the link. 


\section{References}

Acs, Z., Braunerhjelm, P., Audretsch, D., \& Carlsson, B. (2009). The knowledge spillover theory of entrepreneurship. Small Business Economics, 32(1), 15-30.

Adamczyk, A. \& Palmer, I. (2008). Religion and initiation into marijuana use: The deterring role of religious friends. Journal of Drug Issues, 38(3), 717-741.

Aldrich, H. \& Zimmer, C. (1986). Entrepreneurship through social networks. In D. SextonR. Smilor (Eds.), The art and science of entrepreneurship (pp. 3-23). Cambridge, MA: Ballinger Publishing Company.

Alstete, J. W. (2008). Aspects of entrepreneurial success. Journal of small business and enterprise development, 15(3), 584-594.

Anokhin, S. \& Schulze, W. S. (2009). Entrepreneurship, innovation, and corruption. Journal of Business Venturing, 24(5), 465-476.

Åstebro, T. (2003). The return to independent invention: Evidence of unrealistic optimism, risk seeking or skewness loving? Economic Journal, 113(484), 226-239.

Audretsch, D. B., Bönte, W., \& Tamvada, J. P. (2013). Religion, social class, and entrepreneurial choice. Journal of Business Venturing, 28(6), 774-789.

Audretsch, D. B. \& Keilbach, M. (2007). The theory of knowledge spillover entrepreneurship. Journal of Management Studies, 44(7), 1242-1254.

Audretsch, D. B. \& Lehmann, E. E. (2005). Does the knowledge spillover theory of entrepreneurship hold for regions? Research Policy, 34(8), 1191-1202.

Baker, T., Gedajlovic, E., \& Lubatkin, M. (2005). A framework for comparing entrepreneurship processes across nations. Journal of International Business Studies, 36(5), 492-504.

Barney, J. (1991). Firm resources and sustained competitive advantage. Journal of Management, 17(1), 99-120.

Baron, R. M. \& Kenny, D. A. (1986). The moderator-mediator variable distinction in social psychological research: Conceptual, strategic, and statistical considerations. Journal of personality and social psychology, 51(6), 1173-1182.

Barro, R. J. \& McCleary, R. M. (2005). Which countries have state religions? Quarterly Journal of Economics, 120(4), 1331-1370.

Baumol, W. J. (1990). Entrepreneurship: Productive, unproductive, and destructive. Journal of Political Economy, 98(5), 893-921.

Begley, T. M. \& Wee-Liang, T. (2001). The socio-cultural environment for entrepreneurship: A comparison between east asian and anglo-saxon countries. Journal of International Business Studies, 32(3), 537553.

Bergkvist, L. \& Rossiter, J. R. (2007). The predictive validity of multiple-item versus single-item measures of the same constructs. Journal of Marketing Research, 44(2), 175-184.

Block, J., Thurik, R., van der Zwan, P., \& Walter, S. (2013a). Business takeover or new venture? Individual and environmental determinants from a cross-country study. Entrepreneurship Theory and Practice, 37(5), 1099-1121.

Block, J., Thurik, R., \& Zhou, H. (2013b). What turns knowledge into innovative products? The role of entrepreneurship and knowledge spillovers. Journal of Evolutionary Economics, 23(4), 693-718.

Bowen, H. P. \& De Clercq, D. (2008). Institutional context and the allocation of entrepreneurial effort. Journal of International Business Studies, 39(4), 747-767.

Braunerhjelm, P., Acs, Z. J., Audretsch, D. B., \& Carlsson, B. (2010). The missing link: Knowledge diffusion and entrepreneurship in endogenous growth. Small Business Economics, 34(2), 105-125.

Brouwer, M. T. (2002). Weber, schumpeter and knight on entrepreneurship and economic development. Journal of Evolutionary Economics, 12(1/2), 83.

Brush, C. G. (1992). Research on women business owners: Past trends, a new perspective and future directions. Entrepreneurship Theory \& Practice, 16(4), 5-30.

Busenitz, L. W., Gomez, C., \& Spencer, J. W. (2000). Country institutional profiles: Unlocking entrepreneurial phenomena. Academy of Management Journal, 43(5), 993-1003.

Central Intelligence Agency. (2012). The world factbook. https:/www.cia.gov/library/publications/the-worldfactbook/index.html, accessed 2012-05-02.

Chan-Serafin, S., Brief, A. P., \& George, J. M. (2013). How does religion matter and why? Religion and the organizational sciences. Organization Science, 24(5), 1585-1600.

Choi, H. (2010). Religious institutions and ethnic entrepreneurship: The korean ethnic church as a small business incubator. Economic Development Quarterly, 24(4), 372-383.

Collins, C. J., Hanges, P. J., \& Locke, E. A. (2004). The relationship of achievement motivation to entrepreneurial behavior: A meta-analysis. Human Performance, 17(1), 95-117.

Cullen, J. B., Johnson, J. L., \& Parboteeah, K. P. (forthcoming). National rates of opportunity entrepreneurship activity: Insights from institutional anomie theory. Entrepreneurship Theory and Practice.

Dana, L. P. (2009). Religion as an explanatory variable for entrepreneurship. The International Journal of Entrepreneurship and Innovation, 10(2), 87-99. 
Davidsson, P. (1995). Culture, structure and regional levels of entrepreneurship. Entrepreneurship \& Regional Development, 7(1), 41-62.

Davidsson, P. \& Honig, B. (2003). The role of social and human capital among nascent entrepreneurs. Journal of Business Venturing, 18(3), 301-331.

Davie, G. (2007). The sociology of religion. London: Sage.

De Carolis, D. M. \& Saparito, P. (2006). Social capital, cognition, and entrepreneurial opportunities: A theoretical framework. Entrepreneurship: Theory \& Practice, 30(1), 41-56.

DeJong, G. F., Faulkner, J. E., \& Warland, R. H. (1976). Dimensions of religiosity reconsidered: Evidence from a cross-cultural study. Social Forces, 54(4), 866-889.

Drakopoulou Dodd, S. \& Gotsis, G. (2007). The interrelationships between entrepreneurship and religion. The International Journal of Entrepreneurship and Innovation, 8(2), 93-104.

Drakopoulou Dodd, S. \& Seaman, P. T. (1998). Religion and enterprise: An introductory exploration. Entrepreneurship: Theory \& Practice, 23(1), 71-86.

Drees, W. B. (2002). "Playing god? Yes!" religion in the light of technology. Zygon, 37(3), 643-654.

Dyck, B. (in press). God on management: Religion, the 'theological turn', and organizational and management theory and practice. Review in Sociology of Organizations.

Essers, C. \& Benschop, Y. (2009). Muslim businesswomen doing boundary work: The negotiation of islam, gender and ethnicity within entrepreneurial contexts. Human Relations, 62(3), 403-423.

Furnham, A. \& Koritsas, E. (1990). The protestant work ethic and vocational preference. Journal of Organizational Behavior, 11(1), 43-55.

Galbraith, C. S. \& Galbraith, D. M. (2007). An empirical note on entrepreneurial activity, intrinsic religiosity and economic growth. Journal of Enterprising Communities, 1(2), 188-201.

Gallup Organization. (2010). Flash eurobarometer 283 "entrepreneurship in the eu and beyond". http://ec.europa.eu/enterprise/policies/sme/facts-figures-analysis/eurobarometer/fl283_en.pdf, accessed 2011-12-24.

Gotsis, G. \& Kortezi, Z. (2009). The impact of greek orthodoxy on entrepreneurship: A theoretical framework. Journal of Enterprising Communities, 3(2), 152-175.

Griliches, Z. (1990). Patent statistics as economic indicators: A survey. Journal of Economic Literature, 28(4), 1661-1707.

Hamilton, B. H. (2000). Does entrepreneurship pay? An empirical analysis of the returns to self-employment. Journal of Political Economy, 108(3), 604-631.

Hansen, B. A. \& Hansen, M. E. (2008). Religion, social capital and business bankruptcy in the united states, 1921-1932. Business History, 50(6), 714-727.

Hayton, J. C. \& Cacciotti, G. (2013). Is there an entrepreneurial culture? A review of empirical research. Entrepreneurship \& Regional Development, 25(9/10), 708-731.

Hayton, J. C., George, G., \& Zahra, S. A. (2002). National culture and entrepreneurship: A review of behavioral research. Entrepreneurship: Theory \& Practice, 26(4), 33-52.

Hoetker, G. (2007). The use of logit and probit models in strategic management research: Critical issues. Strategic Management Journal, 28(4), 331-343.

Hofmann, D. A. (1997). An overview of the logic and rationale of hierarchical linear models. Journal of Management, 23(6), 723-744.

Hofstede, G. (1980). Culture's consequences: International differences in work related values. Beverly Hills, CA: Sage.

House, R. J., Hanges, P. J., Javidan, M., Dorfman, P. W., \& Gupta, V. (2004). Culture, leadership and organization: The globe study of 62 societies. Thousand Oaks, CA: Sage.

Hunsberger, B. \& Jackson, L. M. (2005). Religion, meaning, and prejudice. Journal of Social Issues, 61(4), 807826.

Iannaccone, L. R., Finke, R., \& Stark, R. (1997). Deregulating religion: The economics of church and state. Economic Inquiry, 35(2), 350-364.

International Monetary Fund. (2010). World economic outlook database. http://www.imf.org/external/pubs/ft/weo/2010/02/weodata/index.aspx accessed 2011-03-29.

Jaffe, A. B., Trajtenberg, M., \& Henderson, R. (1993). Geographic localization of knowledge spillovers as evidenced by patent citations. Quarterly Journal of Economics, 108(3), 577-598.

Keller, W. (2002). Geographic localization of international technology diffusion. American Economic Review, 92(1), 120-142.

Kelley, D., Slavica, S., \& Herrington, M. (2012). The global entrepreneurship monitor. 2011 global report. http://www.gemconsortium.org/docs/download/2201, accessed 2012-07-10.

Kelley, J. \& De Graaf, N. D. (1997). National context, parental socialization, and religious belief: Results from 15 nations. American Sociological Review, 62(4), 639-659.

Kirzner, I. (1973). Competition and entrepreneurship. Chicago: University of Chicago Press.

Kong, L. (2001). Religion and technology: Refiguring place, space, identity and community. Area, 33(4), 404413. 
Kostova, T. (1999). Transnational transfer of strategic organizational practices: A contextual perspective. Academy of Management Review, 24(2), 308-324.

Kwon, S.-W. \& Arenius, P. (2010). Nations of entrepreneurs: A social capital perspective. Journal of Business Venturing, 25(3), 315-330.

Lee, S. H. \& Wong, P. K. (2004). An exploratory study of technopreneurial intentions: A career anchor perspective. Journal of Business Venturing, 19(1), 7-28.

Lévesque, M. \& Minniti, M. (2006). The effect of aging on entrepreneurial behavior. Journal of Business Venturing, 21(2), 177-194.

Li, Y. \& Zahra, S. A. (2012). Formal institutions, culture, and venture capital activity: A cross-country analysis. Journal of Business Venturing, 27(1), 95-111.

Lim, C. \& MacGregor, C. A. (2012). Religion and volunteering in context: Disentangling the contextual effects of religion on voluntary behavior. American Sociological Review, 77(5), 747-779.

Liñán, F. \& Fernandez-Serrano, J. (2014). National culture, entrepreneurship and economic development: Different patterns across the european union. Small Business Economics, 42(4), 685-701.

Lucas Jr, R. E. (1988). On the mechanics of economic development. Journal of Monetary Economics, 22(1), 342.

Martin, B. C., McNally, J. J., \& Kay, M. J. (2013). Examining the formation of human capital in entrepreneurship: A meta-analysis of entrepreneurship education outcomes. Journal of Business Venturing, 28(2), 211-224.

Mascarenhas, O. A. J. (1995). Exonerating unethical marketing behaviors: A diagnostic framework. Journal of Marketing, 59(2), 43.

McMullen, J. S., Bagby, D. R., \& Palich, L. E. (2008). Economic freedom and the motivation to engage in entrepreneurial action. Entrepreneurship: Theory \& Practice, 32(5), 875-895.

Muller, D., Judd, C. M., \& Yzerbyt, V. Y. (2005). When moderation is mediated and mediation is moderated. Journal of personality and social psychology, 89(6), 852-863.

Myers, S. M. (2000). The impact of religious involvement on migration. Social Forces, 79(2), 755-783.

Neubert, M. J. \& Beard, A. (2013). Entrepreneurs feel closer to god than the rest of us do. Harvard Business Review, 91(10), 32-33.

Noble, D. (2013). The religion of technology: The divinity of man and the spirit of invention. Random House LLC.

Norton, E. C., Wang, H., \& Ai, C. (2004). Computing interaction effects and standard errors in logit and probit models. The Stata Journal, 4(2), 154-167.

Ozgen, E. \& Baron, R. A. (2007). Social sources of information in opportunity recognition: Effects of mentors, industry networks, and professional forums. Journal of Business Venturing, 22(2), 174-192.

Parboteeah, K., Hoegl, M., \& Cullen, J. (2008). Ethics and religion: An empirical test of a multidimensional model. Journal of Business Ethics, 80(2), 387-398.

Parboteeah, K. P., Hoegl, M., \& Cullen, J. (2009a). Religious dimensions and work obligation: A country institutional profile model. Human Relations, 62(1), 119-148.

Parboteeah, K. P., Paik, Y., \& Cullen, J. B. (2009b). Religious denominations and work values: A focus on buddhism, christianity, hinduism and islam. International Journal of Cross-cultural Management, 9(1), 51-67.

Pearce Ii, J. A., Fritz, D. A., \& Davis, P. S. (2010). Entrepreneurial orientation and the performance of religious congregations as predicted by rational choice theory. Entrepreneurship: Theory \& Practice, 34(1), 219248.

Pinillos, M.-J. \& Reyes, L. (2011). Relationship between individualist-collectivist culture and entrepreneurial activity: Evidence from global entrepreneurship monitor data. Small Business Economics, 37(1), 23-37.

Ramasamy, B., Yeung, M., \& Au, A. (2010). Consumer support for corporate social responsibility (csr): The role of religion and values. Journal of Business Ethics, 91 61-72.

Rauch, A. \& Frese, M. (2007). Let's put the person back into entrepreneurship research: A meta-analysis on the relationship between business owners' personality traits, business creation, and success. European Journal of Work \& Organizational Psychology, 16(4), 353-385.

Raudenbush, S. W. \& Bryk, A. S. (2002). Hierarchical linear models: Applications and data analysis methods. Newbury Park et al.: Sage.

Romer, P. M. (1990). Endogenous technological change. Journal of Political Economy, 98(5), S71-S102.

Ryman, J. A. \& Turner, C. (2007). The modern weberian thesis: A short review of the literature. Journal of Enterprising Communities, 1(2), 175-187.

Scherer, R. F., Adams, J. S., Carley, S. S., \& Wiebe, F. A. (1989). Role model performance effects on development of entrepreneurial career preference. Entrepreneurship Theory \& Practice, 13(3), 53-71.

Schumpeter, J. A. (1934). The theory of economic development. Cambridge: Havard University Press.

Shane, S. \& Venkataraman, S. (2000). The promise of entrepreneurship as a field of research. Academy of Management Review, 25(1), 217-226.

Stark, R. \& Bainbridge, W. S. (1985). The future of religion. Berkeley: University of California Press.

Stark, R. \& Bainbridge, W. S. (1996). A theory of religion. New Brunswick, N.J.: Rutgers University Press. 
Stephan, U. \& Uhlaner, L. M. (2010). Performance-based vs socially supportive culture: A cross-national study of descriptive norms and entrepreneurship. Journal of International Business Studies, 41(8), 1347-1364.

Stewart Jr., W. H. \& Roth, P. L. (2001). Risk propensity differences between entrepreneurs and managers: A meta-analytic review. Journal of Applied Psychology, 86(1), 145-153.

Stuart, T. E. \& Sorenson, O. (2007). Strategic networks and entrepreneurial ventures. Strategic Entrepreneurship Journal, 1(3-4), 211-227.

Tervo, H. (2006). Regional unemployment, self-employment and family background. Applied Economics, 38(9), $1055-1062$.

Thomas, A. S. (2000). A case for comparative entrepreneurship: Assessing the relevance of culture. Journal of International Business Studies, 31(2), 287-301.

TNS Opinion \& Social. (2010). Eurobarometer 73.1 "biotechnology". Bruxelles.

Uhlaner, L. \& Thurik, R. (2007). Postmaterialism influencing total entrepreneurial activity across nations. Journal of Evolutionary Economics, 17(2), 161-185.

Valliere, D. (2008). Exploring buddhist influence on the entrepreneurial decision. International Journal of Entrepreneurial Behavior and Research, 14(3), 172-191.

Van De Ven, H. (1993). The development of an infrastructure for entrepreneurship. Journal of Business Venturing, 8(3), 211-230.

Verheul, I., Van Stel, A., \& Thurik, R. (2006). Explaining female and male entrepreneurship at the country level. Entrepreneurship \& Regional Development, 18(2), 151-183.

Wanous, J. P. \& Reichers, A. E. (1996). Estimating the reliability of a single-item measure. Psychological Reports, 78(2), 631-634.

Weber, M. (1930). The protestant ethic and the spirit of capitalism. London: Routledge.

Weber, M. ([1922] 1978). Economy and society. Berkely: University of California Press.

White, L. T. (1978). Medieval religion and technology: Collected essays. University of California Press.

World Bank. (2011). World development indicators. http://data.worldbank.org/indicator, accessed 2011-12-25.

World Economic Forum. (2010). The global competitiveness report 2010-2011. http://www3.weforum.org/docs/WEF_GlobalCompetitivenessReport_2010-11.pdf, accessed 2011-0329.

World Values Study Group. (2011). World value surveys. http://www.wvsevsdb.com, accessed 2011-12-24. 
Figure 1 Contingent effect of knowledge investments on the relationship between the cognitive aspect and self-employment

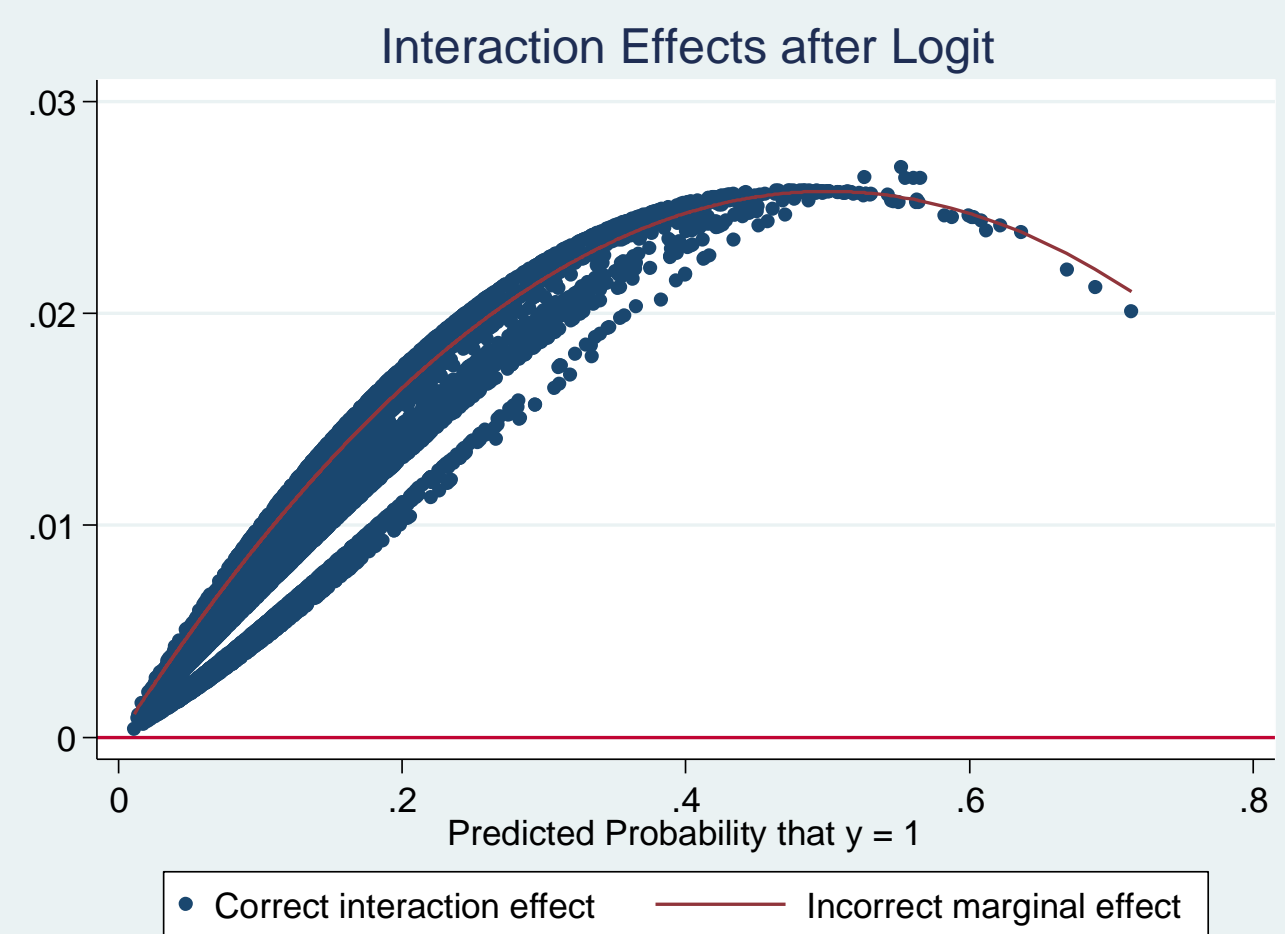

Figure 2 Contingent effect of knowledge investments on the relationship between the normative aspect and self-employment

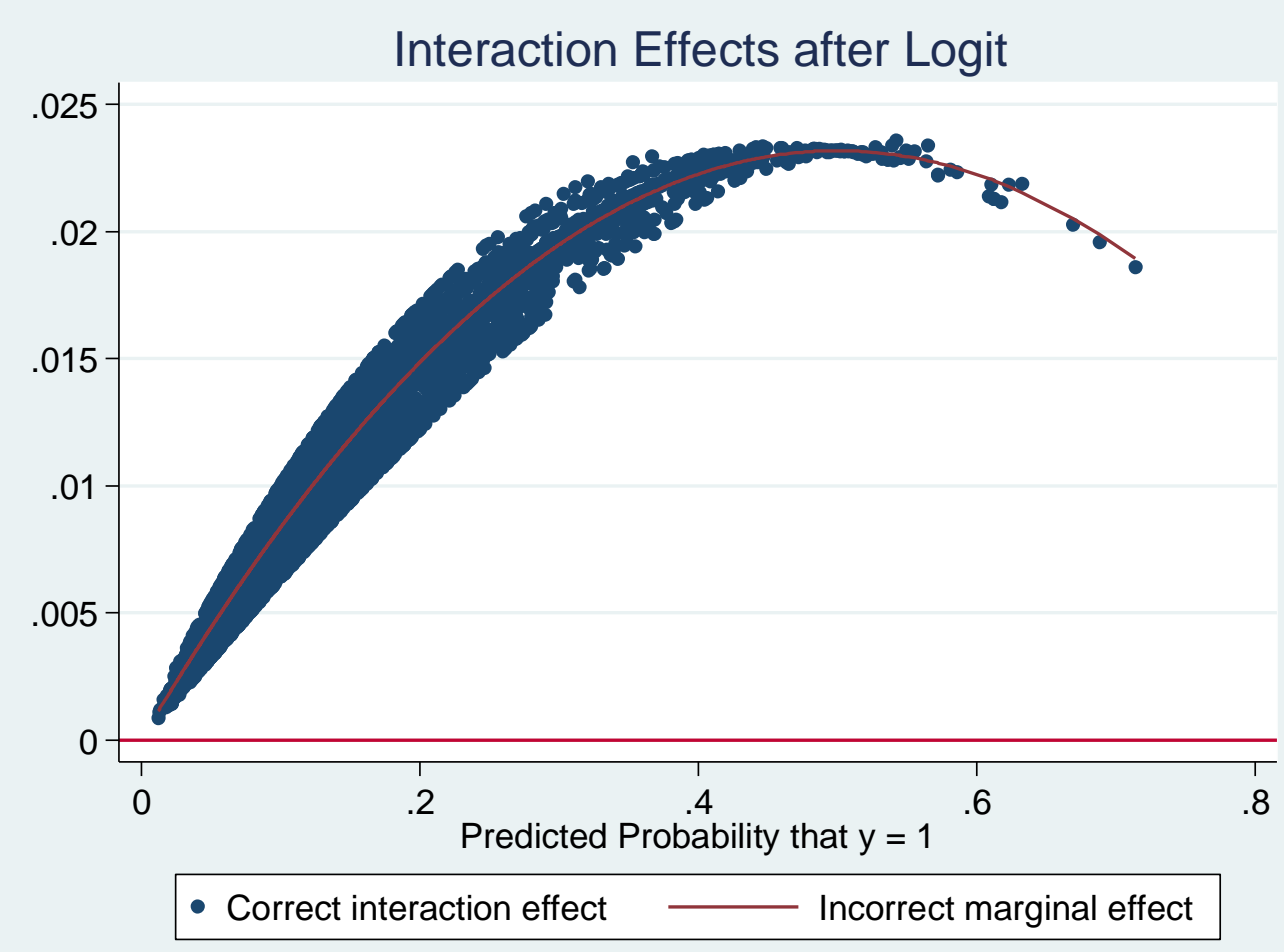


Table 1 Countries in the sample

\begin{tabular}{|c|c|c|c|c|c|c|c|c|}
\hline Country & $\begin{array}{l}\text { Sample } \\
\text { size }\end{array}$ & $\begin{array}{c}\text { Self-employment } \\
\text { rate }^{\mathrm{a}}\end{array}$ & $\begin{array}{c}\text { Unemployment rate } \\
(2010)^{\mathrm{a}}\end{array}$ & $\begin{array}{c}\text { Cognitive } \\
\text { aspect }^{\mathrm{b}}\end{array}$ & $\begin{array}{c}\text { Normative } \\
\text { aspect }^{\text {b }}\end{array}$ & $\begin{array}{c}\text { Regulative } \\
\text { aspect }^{\mathrm{b}}\end{array}$ & $\begin{array}{c}\text { Knowledge } \\
\text { investments }^{c}\end{array}$ & $\begin{array}{l}\text { Patent applications }^{\mathrm{c}} \\
\text { (ln) }\end{array}$ \\
\hline 1Belgium & 359 & 0.12 & 8.40 & -0.54 & 0.24 & 0.00 & 0.44 & 3.88 \\
\hline 2Bulgaria & 224 & 0.16 & 10.20 & -0.75 & 0.15 & 0.00 & -1.10 & 0.74 \\
\hline 3Croatia & 203 & 0.19 & 11.97 & 0.75 & 0.40 & 0.00 & -0.84 & 1.10 \\
\hline 4Czech Republic & 467 & 0.22 & 7.30 & -1.42 & 0.12 & 0.00 & -0.02 & 1.55 \\
\hline 5Denmark & 326 & 0.10 & 7.52 & -1.24 & 0.10 & 1.00 & 1.23 & 4.26 \\
\hline 6Estonia & 251 & 0.16 & 16.90 & -1.23 & 0.09 & 0.00 & -0.45 & 0.41 \\
\hline 7Finland & 245 & 0.25 & 8.40 & 0.05 & 0.19 & 1.00 & 1.75 & 5.05 \\
\hline 8France & 512 & 0.11 & 9.70 & -0.85 & 0.11 & 0.00 & 0.60 & 3.93 \\
\hline 9Germany & 509 & 0.19 & 6.80 & -1.20 & 0.17 & 0.00 & 1.15 & 4.68 \\
\hline 10Greece & 494 & 0.32 & 12.50 & 0.41 & 0.31 & 1.00 & -1.12 & 0.74 \\
\hline 11Hungary & 431 & 0.18 & 11.20 & 0.07 & 0.20 & 0.00 & -0.82 & 1.89 \\
\hline 12Iceland & 360 & 0.18 & 7.60 & 0.29 & 0.20 & 1.00 & 0.90 & 4.45 \\
\hline 13Ireland & 242 & 0.21 & 13.50 & 1.27 & 0.66 & 1.00 & -0.13 & 3.62 \\
\hline 14Italy & 532 & 0.24 & 8.44 & 0.77 & 0.48 & 1.00 & -0.51 & 3.14 \\
\hline 15Latvia & 194 & 0.14 & 18.97 & -0.36 & 0.23 & 0.00 & -1.00 & -0.92 \\
\hline 16Lithuania & 247 & 0.15 & 17.80 & 0.77 & 0.22 & 0.00 & -0.68 & 1.16 \\
\hline 17Luxembourg & 243 & 0.14 & 4.40 & -0.43 & 0.22 & 1.00 & 0.43 & 3.93 \\
\hline 18Malta & 175 & 0.13 & 6.90 & 1.77 & 0.82 & 1.00 & -0.95 & 1.59 \\
\hline 19Netherlands & 537 & 0.19 & 4.50 & -0.72 & 0.21 & 0.00 & 0.40 & 4.39 \\
\hline 20Poland & 450 & 0.25 & 9.60 & 1.33 & 0.64 & 0.00 & -0.90 & 0.34 \\
\hline 21Romania & 161 & 0.15 & 6.90 & 1.25 & 0.47 & 0.00 & -1.10 & -0.51 \\
\hline 22Slovakia & 215 & 0.17 & 14.40 & 0.42 & 0.45 & 0.00 & -0.83 & -0.11 \\
\hline 23Slovenia & 189 & 0.13 & 7.20 & -0.89 & 0.30 & 0.00 & 0.04 & 1.95 \\
\hline 24Spain & 525 & 0.19 & 20.07 & 0.07 & 0.29 & 1.00 & -0.32 & 1.92 \\
\hline 25Sweden & 245 & 0.11 & 8.37 & -1.07 & 0.23 & 1.00 & 1.64 & 4.75 \\
\hline 26United Kingdom & 443 & 0.17 & 7.90 & -0.07 & 0.19 & 1.00 & 0.52 & 3.93 \\
\hline 27United States of America & 487 & 0.29 & 9.63 & 1.54 & 0.59 & 0.00 & 1.33 & 5.53 \\
\hline
\end{tabular}

${ }^{\mathrm{a}}$ Source: IMD World Competitiveness Yearbook, ${ }^{\mathrm{b}}$ Source: World Values Survey. ${ }^{\mathrm{c}}$ Source: World Development Indicators and Global Competitiveness Report. 
Table 2 Descriptive statistics and correlations ${ }^{\mathrm{a}}$

\begin{tabular}{|c|c|c|c|c|c|c|c|c|c|c|c|c|c|c|c|c|c|c|c|}
\hline Variable & $\mathbf{M}$ & SD & 1 & 2 & 3 & 4 & 5 & 6 & 7 & 8 & 9 & 10 & 11 & 12 & 13 & 14 & 15 & 16 & 17 \\
\hline 1.Entrepreneurial activity & 0.19 & 0.39 & - & & & & & & & & & & & & & & & & \\
\hline 2.Cognitive aspect & 0.00 & 0.95 & $0.41^{*}$ & - & & & & & & & & & & & & & & & \\
\hline 3. Normative aspect & 0.31 & 0.19 & 0.29 & $0.86^{* * *}$ & - & & & & & & & & & & & & & & \\
\hline $\begin{array}{l}\text { 4. Regulative aspect } \\
\text { Knowledge }\end{array}$ & 0.41 & 0.50 & 0.09 & 0.15 & 0.12 & - & & & & & & & & & & & & & \\
\hline 5.investments & 0.00 & 0.92 & -0.08 & $-0.38^{*}$ & $-0.34^{\mathrm{t}}$ & 0.30 & - & & & & & & & & & & & & \\
\hline 6.Gdp (ppp) per capita & 30909.7814 & 4184.45 & 0.01 & -0.14 & -0.08 & $0.47^{*}$ & $0.60^{* *}$ & - & & & & & & & & & & & \\
\hline 7.Age & 44.11 & 10.76 & $0.08^{* * *}$ & $-0.04^{* * *}$ & $-0.04^{* * * *}$ & $-0.06^{* * * *}$ & $0.10^{* * * *}$ & $0.03^{* *}$ & - & & & & & & & & & & \\
\hline 8.Male & 0.46 & 0.50 & $0.14^{* * *}$ & $0.02^{\mathrm{t}}$ & $0.03^{*}$ & $0.05^{* * *}$ & $0.04^{* * *}$ & $0.02^{*}$ & -0.01 & - & & & & & & & & & \\
\hline 9.Education level & 14.24 & 3.24 & 0.00 & 0.01 & -0.01 & -0.01 & $0.11^{* * *}$ & $0.03^{* *}$ & $-0.06^{* * *}$ & -0.01 & - & & & & & & & & \\
\hline 10.Self-employed father & 0.21 & 0.41 & $0.14^{* * *}$ & 0.02 & 0.01 & $0.16^{* * *}$ & $0.09^{* * * *}$ & $0.12^{* * *}$ & -0.01 & 0.01 & $0.03^{* *}$ & - & & & & & & & \\
\hline 11.Self-employed mother & 0.09 & 0.28 & $0.11^{* * *}$ & $0.02^{\mathrm{t}}$ & 0.00 & $0.07^{* * *}$ & $0.05^{* * * *}$ & $0.05^{* * *}$ & 0.00 & -0.01 & $0.02^{*}$ & $0.41^{* * *}$ & - & & & & & & \\
\hline 12.Risk tolerance & 2.78 & 0.79 & $0.13^{* * *}$ & $0.10^{* * * *}$ & $0.12^{* * * *}$ & $0.06^{* * * *}$ & $0.04^{\text {**** }}$ & $0.06^{* * * *}$ & $-0.09^{* * *}$ & $0.11^{* * * *}$ & $0.06^{* * *}$ & $0.05^{* * * *}$ & $0.04^{* * *}$ & - & & & & & \\
\hline 13.Self-confidence & 3.11 & 0.64 & $0.07^{* * *}$ & $0.06^{* * *}$ & $0.05^{* * *}$ & $0.06^{* * *}$ & $0.13^{\text {*** }}$ & $0.09^{* * * *}$ & 0.00 & $0.06^{* * *}$ & $0.06^{* * *}$ & $0.03^{* *}$ & $0.02^{\mathrm{t}}$ & $0.25^{* * * *}$ & - & & & & \\
\hline 14.Int. locus of control & 3.17 & 0.70 & $0.06^{* * *}$ & $0.07^{* * *}$ & $0.06^{* * * *}$ & $0.02^{t}$ & $0.08^{* * *}$ & $0.05^{* * *}$ & -0.02 & $0.02^{\mathrm{t}}$ & $0.03^{* *}$ & 0.00 & 0.00 & $0.15^{* * *}$ & $0.27^{* * *}$ & - & & & \\
\hline 15.Inventiveness & 3.09 & 0.67 & $0.11^{* * *}$ & $0.08^{* * *}$ & $0.06^{* * *}$ & $0.05^{* * *}$ & $0.04^{* * *}$ & $0.07^{* * *}$ & $-0.03^{* *}$ & $0.07^{* * *}$ & $0.10^{* * *}$ & $0.05^{* * *}$ & $0.03^{* *}$ & $0.27^{* * *}$ & $0.31^{* * *}$ & $0.22^{* * *}$ & - & & \\
\hline 16.Desire for competition & 2.65 & 0.84 & $0.07^{* * *}$ & $0.15^{* * *}$ & $0.13^{* * *}$ & $0.08^{* * *}$ & 0.01 & $0.07^{* * *}$ & $-0.08^{* * *}$ & $0.19^{* * *}$ & -0.01 & $0.04^{* * *}$ & 0.00 & $0.30^{* * *}$ & $0.21^{* * *}$ & $0.15^{* * *}$ & $0.21^{* * *}$ & - & \\
\hline 17.Optimism & 3.04 & 0.75 & $0.05^{* * *}$ & $0.04^{* * *}$ & $0.05^{* * *}$ & $0.05^{* * *}$ & $0.16^{* * *}$ & $0.11^{* * *}$ & $-0.07^{* * *}$ & $0.02^{*}$ & $0.12^{* * *}$ & $0.03^{* *}$ & $0.02^{*}$ & $0.22^{* * *}$ & $0.31^{* * *}$ & $0.25^{* * *}$ & $0.27^{* * * *}$ & $0.20^{* * *}$ & - \\
\hline 18.Perc. qual. of entr. edu. & 2.32 & 0.72 & $0.08^{* * *}$ & $0.10^{* * *}$ & $0.11^{* * *}$ & -0.01 & $0.05^{* * *}$ & $0.03^{*}$ & $-0.03^{* *}$ & $0.05^{* * *}$ & $0.17^{* * *}$ & $0.05^{* * *}$ & $0.04^{* * *}$ & $0.16^{* * *}$ & $0.11^{* * *}$ & $0.09^{* * *}$ & $0.16^{* * *}$ & $0.17^{* *}$ & $0.15^{* * *}$ \\
\hline
\end{tabular}

${ }^{a} n=9,266$ for evaluating pairwise correlations between individual-level variables or between individual- and country-level variables; $n=27$ for evaluating pairwise correlations between country-level variables.

${ }^{t} \mathrm{p}<.10$

${ }^{*} \mathrm{p}<.05$

$*_{* * * *} \mathrm{p}<.01$

$\mathrm{p}<.001$ (two-tailed test) 
Table 3 Regression results for entrepreneurial activity ${ }^{\text {a }}$

\begin{tabular}{|c|c|c|c|c|c|c|c|c|c|c|}
\hline & \multicolumn{2}{|l|}{ Model 1} & \multicolumn{2}{|l|}{ Model 2} & \multicolumn{2}{|l|}{ Model 3} & \multicolumn{2}{|l|}{ Model 4} & \multicolumn{2}{|l|}{ Model 5} \\
\hline & $\mathbf{B}$ & S.E. & B & S.E. & B & S.E. & B & S.E. & B & S.E. \\
\hline \multicolumn{11}{|l|}{ Control variables } \\
\hline Age & $0.02^{* * * *}$ & 0.00 & $0.02^{* * *}$ & 0.00 & $0.02^{* * * *}$ & 0.00 & $0.02^{* * * *}$ & 0.00 & $0.02^{* * * *}$ & 0.00 \\
\hline Male & $0.69^{* * * *}$ & 0.07 & $0.69^{* * *}$ & 0.07 & $0.69^{* * * *}$ & 0.07 & $0.70^{* * * *}$ & 0.07 & $0.69^{* * * *}$ & 0.07 \\
\hline Education level & -0.01 & 0.01 & -0.01 & 0.01 & -0.01 & 0.01 & -0.01 & 0.01 & -0.01 & 0.01 \\
\hline Self-employed father & $0.65^{* * *}$ & 0.06 & $0.66^{* * *}$ & 0.06 & $0.66^{* * *}$ & 0.06 & $0.66^{* * * *}$ & 0.06 & $0.65^{* * *}$ & 0.06 \\
\hline Self-employed mother & $0.46^{* * * *}$ & 0.09 & $0.46^{* * *}$ & 0.09 & $0.46^{* * * *}$ & 0.09 & $0.46^{* * *}$ & 0.09 & $0.46^{* * * *}$ & 0.08 \\
\hline Risk tolerance & $0.31^{* * * *}$ & 0.03 & $0.31^{* * *}$ & 0.03 & $0.31^{* * * *}$ & 0.03 & $0.31^{* * * *}$ & 0.03 & $0.31^{* * * *}$ & 0.03 \\
\hline Self-confidence & -0.02 & 0.06 & -0.02 & 0.06 & -0.02 & 0.06 & -0.02 & 0.06 & -0.02 & 0.06 \\
\hline Internal locus of control & 0.07 & 0.06 & 0.07 & 0.06 & 0.07 & 0.06 & 0.07 & 0.06 & 0.07 & 0.06 \\
\hline Inventiveness & $0.24^{* * * *}$ & 0.04 & $0.24^{* * *}$ & 0.04 & $0.24^{* * * *}$ & 0.04 & $0.24^{* * *}$ & 0.04 & $0.24^{* * * *}$ & 0.04 \\
\hline Desire for competition & -0.02 & 0.03 & -0.02 & 0.03 & -0.02 & 0.03 & -0.02 & 0.03 & -0.02 & 0.03 \\
\hline Optimism & 0.03 & 0.06 & 0.03 & 0.06 & 0.03 & 0.06 & 0.03 & 0.06 & 0.03 & 0.06 \\
\hline Perc. qual. of entrepreneurship education & $0.16^{* *}$ & 0.05 & $0.16^{* *}$ & 0.05 & $0.16^{* *}$ & 0.05 & $0.16^{* *}$ & 0.05 & $0.16^{* *}$ & 0.05 \\
\hline GDP (ppp) per capita & -0.06 & 0.07 & 0.05 & 0.09 & -0.01 & 0.08 & -0.05 & 0.08 & -0.02 & 0.07 \\
\hline \multicolumn{11}{|l|}{ Main effects } \\
\hline Cognitive aspect & & & $0.25^{t}$ & 0.13 & 0.14 & 0.11 & 0.16 & 0.13 & $0.28^{*}$ & 0.13 \\
\hline Normative aspect & & & -0.12 & 0.13 & -0.01 & 0.11 & 0.01 & 0.11 & -0.16 & 0.13 \\
\hline Regulative aspect & & & -0.08 & 0.08 & -0.03 & 0.07 & 0.00 & 0.08 & -0.06 & 0.08 \\
\hline Knowledge investments & & & -0.08 & 0.10 & -0.06 & 0.09 & -0.01 & 0.10 & 0.07 & 0.11 \\
\hline \multicolumn{11}{|l|}{ Interaction effects } \\
\hline Cognitive aspect $\mathrm{x}$ & & & & & & & & & & \\
\hline knowledge investments & & & & & $0.17^{*}$ & 0.06 & & & & \\
\hline Normative aspect $\mathrm{x}$ & & & & & & & & & & \\
\hline knowledge investments & & & & & & & $0.18^{*}$ & 0.07 & & \\
\hline Regulative aspect $\mathrm{x}$ & & & & & & & & & & \\
\hline knowledge investments & & & & & & & & & -0.19 & 0.15 \\
\hline Deviance (-2 log likelihood) & 25227.37 & & 25219.77 & & 25214.00 & & 25214.35 & & 25218.51 & \\
\hline Deviance Difference (Chi-sqr) & $631.23^{* * * *}$ & & $638.83^{* * * *}$ & & $644.59^{\text {**** }}$ & & $644.24^{* * *}$ & & $640.08^{* * * *}$ & \\
\hline
\end{tabular}

